\title{
Study of hardness and flexural strength of banyan and peepal fibre reinforced hybrid composites
}

\author{
V.Durga Prasada Rao ${ }^{1, *}$, G.Moses Dayan ${ }^{2}$, V.Navya Geethika ${ }^{3}$ \\ 1, ${ }^{*}$ Dept. of Mechanical Engg., S.R.K.R. Engineering College, Bhimavaram, AP, INDIA Email: vdp009@gmail.com \\ ${ }^{2}$ Dept. of Mech. Engg., S.R.K.R.Engineering College, Bhimavaram,AP, INDIA, Email:mechday@gmail.com \\ ${ }^{3}$ Dept. of Mechanical Engg., S.R.K.R. Engineering College, Bhimavaram, AP, INDIA Email: vng.mini@gmail.com
}

\begin{abstract}
In the present work, Banyan and Peepal fibre reinforced hybrid composites are prepared through hand Lay- up technique.. The objective of the work is to investigate the hardness and flexural properties of eight varieties of banyan - peepal hybrid composites. The composites include banyan-peepal-banyanpeepal-banyan fibre composite, peepal-banyan-peepal-banyan-peepal fibre composite, banyan-copperbanyan-copper-banyan fibre composite (F1-Cu-F1-Cu-F1), peepal-copper-peepal-copper-peepal fibre composite, banyan-peepal-copper-peepal-banyan fibre composite, peepal-copper-banyan-copper-peepal fibre composite, peepal-banyan-copper-banyan-peepal fibre composite, and banyan-copper-peepal-copperbanyan fibre composite . Each of these composites is prepared in $0^{0}$ orientations (i.e., fibres parallel each other), $45^{\circ}$ (i.e., fibres at $45^{\circ}$ to each other) and $90^{\circ}$ orientations (i.e., fibres perpendicular to each other). It is observed from the results that, the hardness of $\mathrm{F} 2-\mathrm{Cu}-\mathrm{F} 1-\mathrm{Cu}-\mathrm{F} 2$ composite with $90^{\circ}$ orientation is high and that of F1-F2-F1-F2-F1 composite with $45^{\circ}$ orientation is low. It is also noticed that, the bending strength of F2-Cu-F1-Cu-F2 composite with $0^{0}$ orientation is high and that of F2-F1-F2-F1-F2 composite with $45^{0}$ orientation is low, and as far as the composites with $90^{\circ}$ orientations are considered, no results are obtained. Further it is noticed that, the hardness of all the eight composites with $90^{\circ}$ orientation is found to be high compared to their remaining orientations and also the hardness of all the composites with $45^{\circ}$ orientation is low compared to their $0^{\circ}$ and $90^{\circ}$ orientations
\end{abstract}

Keywords: hybrid composites, hand lay up technique, hardness,flexural properties

\section{Introduction}

Composites provide characteristics that are not obtainable from any discrete material. They are multifunctional material systems and cohesive structures made by combining two or more compatible materials. Physically, the constituent materials of a composite are different in composition and characteristics. The natural fibre composites are more environmental friendly, and are used in transportation applications (automobiles, railway coaches, aerospace), military applications, building and construction industries (ceiling paneling, partition boards), packaging, consumer products, etc. Their renewability, low density, price and satisfactory mechanical properties make them an attractive ecological alternative to glass, carbon and man-made fibres used in the fabrication of fibre composites. Joshi et.al [1] studied glass fibre reinforced composites and natural fibre composites in terms of their life cycle environmental performance and found that, environmentally natural composites are superior in the specific applications studied. Rana et al. [2] in their work showed that the mechanical properties of jute fibres increase by the use of compatibilizer. At a load of $60 \%$ by weight of fibre, the use of the compatibilizer improved the flexural strength as high as $100 \%$, impact strength by $175 \%$, and tensile strength to $120 \%$. Shah and Lakkad [3] compared the mechanical properties of jute reinforces and glassreinforces and found that, when introduced into the resin matrix as reinforcement, the mechanical properties of jute fibres considerably improved, but it is much lower than that by the introduction of glass and other high performance fibres. Ray et.al [4] has considered jute fibres, done alkali treatment with $5 \% \mathrm{NaOH}$ solution for 0 to $8 \mathrm{hrs}$ with $2 \mathrm{hrs}$ increment at $30^{\circ} \mathrm{C}$, and found that there was an improvement in the properties both for fibres and reinforced composites. Actually after the $\mathrm{NaOH}$ treatment, the fibres have got increased crystallinity, less hemi cellulose content, reduced amount of defects, therby superior bonding with the vinyl ester resin. Saha et.al [5] investigated physical-chemical properties of jute fibres after being treated with alkali $(\mathrm{NaOH})$ solution. It was revealed by the SEM investigation that the fibre-matrix adhesion was improved due to the chemical bonds between fibre and matrix which was provided by the coupling agent. Monteiro S.N.Rodriquez et.al [6] tried to fabricate low cost composites using sugar cane bagasse waste as reinforcement to polymeric resins. They concluded that, the mechanical properties similar to wooden agglomerates can be achieved by fabricating composites

\footnotetext{
Corresponding author: vdp009@gmail.com
} 
with homogenous microstructures. Hassan et.al [7] reported in their work about the dimensional stability and mechanical properties of the composites prepared by converting the bagasse into a thermo formable material through esterification. Ramesh et al. [8] considered jute, sisal and glass fibre reinforced polyester composites and investigated their mechanical properties. They observed that maximum tensile strength has been obtained for the composite prepared by adding glass fibre to jute fibre. They also observed that maximum flexural strength was obtained for jute and sisal mixture composites, and sisal fibre composite has got the maximum impact strength. Alavudeen et al. [9] studied the mechanical properties of woven banana fibre, kenaf fibre and banana/ kenaf hybrid fibre composites. They found that, owing to the hybridization of kenaf with banana fibres, the mechanical strength of woven banana/kenaf fibre hybrid composites increases. Also the tensile, impact, and flexural strengths of the hybrid composites are superior to those of the individual banana and kenaf fibres.

After reviewing the available literature on natural fibre reinforced composites, it is observed that a fair amount of research on natural fibre reinforced polymer composites has been carried out, but little work on Banyan and Peepal fibre composites is evidenced so far. This enlightened the scope for the present study which demonstrates alkali treated and cured Banyan and Peepalfibres, and their effect on the mechanical performance of the fibres in terms of their flexural and hardness properties.

\section{Experimental work}

The Fabrication and testing of natural fibre reinforced composites includes

- Preparation of composites by hand lay-up method.

- Cutting samples of desired dimensions from fabricated composite laminates.

- Hardness test of samples of fabricated composites.

- Bending test of samples of fabricated composites.

The raw materials used in the experimental work are

- Banyan root and Peepal bast fibres

- Epoxy resin LY556(GP) and hardener

- Copper foil

\subsection{Banyan tree}

Banyan tree is characterized by a tangle of branches, roots and trunks. The tree, which may spread across several acres, is deeply rooted. The tree bears fruits, which look like figs. The fruits when matured appear red in colour and are not edible. Paper can be directly made from the wood and bark of the banyan tree. The roots of the tree are used to make ropes, which help to secure wood bundles. A strong adhesive, called shellac, is produced by the sap of the tree. Also its sap is used as a medicine for treating external skin inflammations, dysentery, toothaches and ulcers. Its bark and seeds are used for producing a herbal tonic which can cool the body. Figure 1 shows the banyan fibre after extraction.

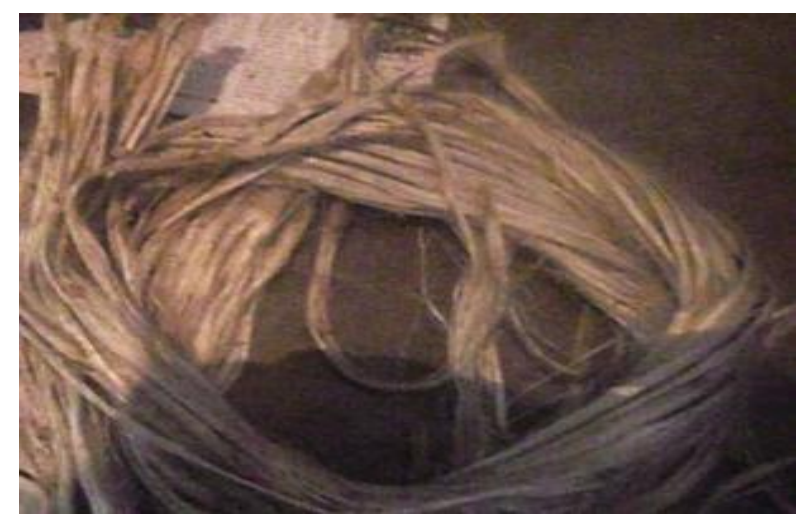

Fig. 1. Banyan fibre after extraction

\subsection{Peepal tree}

The peepal tree is a deciduous tree, native to India is also known as the "bodhi" tree. The Peepal tree, Ficus Religiosa, is a species of the Sacred Fig tree. Its bark is light grey, smooth to touch and peels off easily. The bright green leaves of the tree are shedded in the summer months of March and April. The fruit borne by this big tree, which is a small type of fig, ripens by the month of May. Peepal tree is easily propagated through the cutting or the seeds. Figure 2 shows the peepal fibre after extraction.

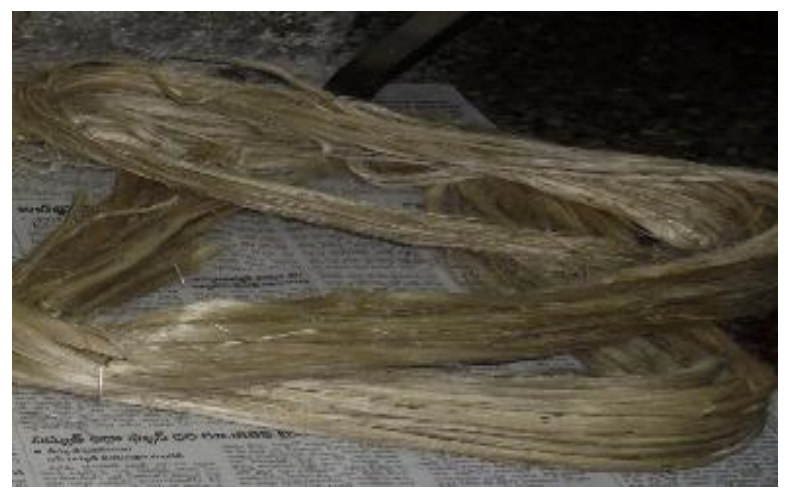

Fig.2.Peepal fibre after extraction

\subsection{Epoxy grade resin}

One of the best systems to use for applications that will be subject to water immersion and marine environments is Epoxy/polyamide based resins. It retains its physical properties even after prolonged water immersion and provides excellent resistance to acidic and caustic exposure and salt water. Epoxy/polyamide resin system is specially prepared for use in high strength bonding applications to provide structural strength to a class of marine and building application and for structural fibre glassing. It cures even in humid and temperature conditions. It is cured generally at room temperature, but can be snap cured for a short period of time at elevated temperature. Figure 3 shows the epoxy resin used in the present work (LY556-GP) for the preparation of composites. 


\subsection{Epoxy Hardener}

Physical properties of the epoxy resin system such as tensile, compression, flexural properties, etc., are influenced by epoxy hardeners. Epoxy hardeners provide gel time, mixed viscosity and de mould time to the epoxy resin system. They are not catalysts but react with the epoxy resins, greatly contributing to the ultimate properties of the cured epoxy resin system. The performance of epoxy hardeners in the resin system depend on its physical characteristics while applying the epoxy resin system, and also the chemical characteristics of the epoxy resins.

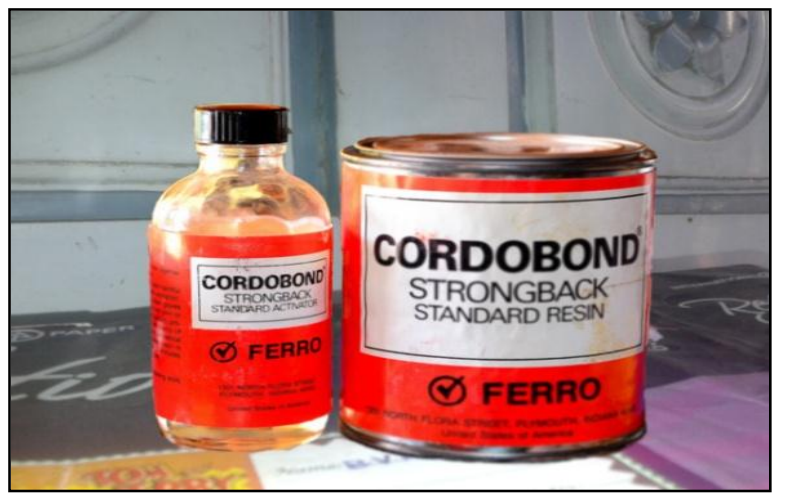

Fig.3. Epoxy grade resin

The physical characteristics of the epoxy resins influencing the behaviour of epoxy hardeners in the epoxy resin system are temperature of the work area, temperature of the resin system (i.e., the heated resins) and moisture (dampness). The chemical characteristics of the epoxy resins that influence the performance of epoxy hardener are the amount and kind of diluents and fillers in epoxy resins, and its viscosity.

\subsection{Copper foil}

Copper is one of the ancient materials used by human beings. The most common alloying elements of copper are tin, zinc aluminium, nickel and silicon. Owing to excellent electrical conductivity, copper has its major application in the electronics industry. Besides the thermal conductivity, it has good strength and fatigue resistance, excellent corrosion resistance and ease of fabrication. These make copper and its alloys such extensively used materials.

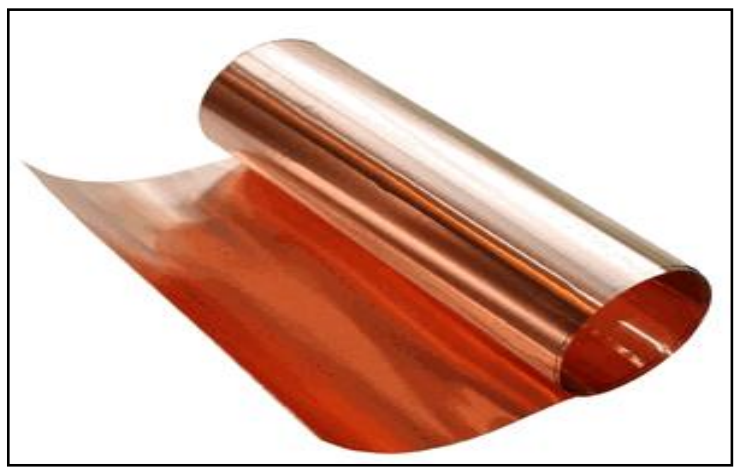

Fig. 4. Copper foil
The mechanical properties of copper strongly depend on its microstructure. As far as the rolled copper foils of different temper are considered, the minimal required ultimate tensile strength and fracture strain at room temperature depend on the area and density of foil which is technical measure of thickness of a foil. Thinner foils have lower numbers in strength and fracture strain. Figure 4 shows the copper foil used in the preparation of composites.

\subsection{Fibre preparation}

The raw banyan roots and peepal bast are cleaned first with water and dried. Then by hand slitting the aggregations is gently dispersed and their outer shells are removed by the knife. Later the fibres are treated with $7 \% \mathrm{NaOH}$ solution. The $\mathrm{NaOH}$ treatment increases the surface area of the fibre by removing the cementing material present in the fibres namely lignin and hemicelluloses. This increase in surface area of the fibre leads to better adhesion of the fibre and matrix, thus increasing the tensile strength. Later the fibres are properly dried. Finally the fibres are cut into required length and kept aside after being measured for required proportion of weight.

\subsection{Mould preparation}

At first the moulds of size $150 \mathrm{~mm} \mathrm{X} 40 \mathrm{~mm}$ X $6 \mathrm{~mm}$ are produced for the fabrication of required composites. A clean smooth surfaced wooden board is taken and washed thoroughly, and then it is covered with a nonreactive thin plastic sheet. Later a glass plate of equal size (thickness $=3 \mathrm{~mm}$ ) to that of the board is taken. The glass is placed on the wooden board. Square bits after being cut to sizes of $8 \mathrm{~mm}$ in desired dimensions are nailed surrounding the glass. These bits are to be nailed in such a way that no polymer leaks out while preparing the composites. Also the bits are carefully nailed so that the glass does not move aside and the overall dimensions of the mould are not distorted. The glass structure is smoothly taken out after the nailing of bits is completed, leaving behind the mould of desired dimensions.

\subsection{Polymer-hardener mixture preparation}

For the making of good composite, the measurements of the polymer - hardener mixture is to be accurate and it should be very uniform. While preparing the mixture, an accurate amount of polymer and $10 \%$ of its hardener are taken and this mixture is stirred thoroughly till it becomes a bit warm. A small extra amount of hardener is generally taken to account for the wastage in the process. Minute amounts of hardener should be taken each time during the preparation of mixture because little extra amount of hardener can spoil the composite. In the present work, hardener HY951 (araldite) which has a viscosity of $10-20$ poise at $25^{\circ} \mathrm{C}$ is used. 


\subsection{Hand lay-up technique for preparing the composites}

After the natural fibre plies were cut to required sizes, three numbers of plies were taken for fabrication of each composite. Then the correct proportions of fibres, and accordingly the resin and hardeners were weighed. Epoxy and hardener were mixed in a bowl by using glass rod. Care was taken to avoid formation of bubbles in the mixture because the trapped air bubbles in matrix may result in failure of the material. The subsequent fabrication process consists of first putting a releasing film on the mould surface, and applying a polymer coating on it. Then the first fibre ply of one kind was put, proper rolling was done, and then resin matrix was again applied. Next to it the fibre ply of another kind was put, and compression was done using compression pads after rolling has been done. This procedure was repeated until a total of five alternating fibres have been laid on e by one. To ensure a good surface finish, a polymer coating is done on the top of the last ply of fibre. Finally a releasing film was kept on the top, light rolling was carried out, and then a $20 \mathrm{~kg}$ weight was applied on the composite. The weight was left for 1 day to allow sufficient time for curing and subsequent hardening of the composite. Figure 5 illustrates the hand lay-up technique used in the preparation of composites.

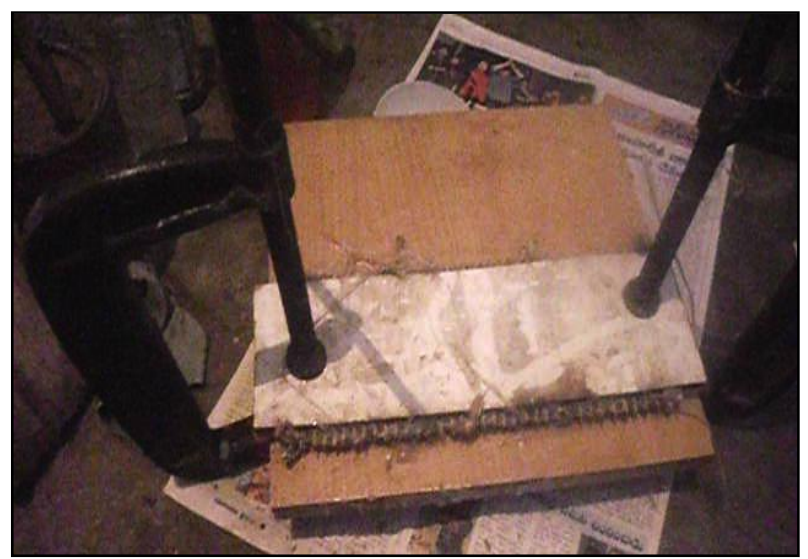

Fig.5. Hand lay-up technique for composites preparation

In the present work, the hybrid composite specimens were fabricated from Banyan fibre, Peepal fibre, Copper foil and polymer-hardener matrix. The weight fractions of composites were maintained at $30 \%$ fibre, $55 \%$ resin and $15 \%$ foil. In this work actually eight varieties of hybrid composites in three different configurations $\left(0^{0}\right.$, $45^{\circ}$ and $90^{\circ}$ orientations) are prepared by hand lay-up technique. Five plies of fibre were used in each hybrid composite. The eight varieties of hybrid composites under consideration are:

- F1-F2-F1-F2-F1,

- F2-F1-F2-F1-F2,

- F1-Cu-F1-Cu-F1

- $\mathrm{F} 2-\mathrm{Cu}-\mathrm{F} 2-\mathrm{Cu}-\mathrm{F} 2$

- $\mathrm{F} 1-\mathrm{F} 2-\mathrm{Cu}-\mathrm{F} 2-\mathrm{F} 1$

- $\mathrm{F} 2-\mathrm{Cu}-\mathrm{F} 1-\mathrm{Cu}-\mathrm{F} 2$

- F2-F1-Cu-F1-F2
- F1-Cu-F2-Cu-F1

where $\mathrm{F} 1$ - Banyan fibre,

F2 - Peepal fibre, and $\mathrm{Cu}$ - Copper foil

After the hybrid composites are fabricated, the specimens are cut in the desired shape to test the mechanical and flexural properties of the banyan-peepal natural hybrid composites. Shore-A hardness tester is used for the hardness testing, and Universal Testing Machine is used for bending test on the samples of composites under consideration.

\subsection{Hardness test}

The hardness testing of plastics is most commonly done by the Shore (Durometer) test or the Rockwell hardness test. According to standards, the hardness test on the fabricated composites is done for determining the resistance of the composites for plastic deformation. Shore hardness is a measure of the resistance of material to indentation by 3 spring loaded indenter. The higher the hardness number, the greater is the resistance. Samples used for hardness testing are shown in Figure 6. The dimensions of specimen are $200 \mathrm{~mm}$ X $30 \mathrm{~mm} \mathrm{X} 5$ $\mathrm{mm}$. The Shore $-\mathrm{A}$ hardness tester used in the study is shown in Figure 7.

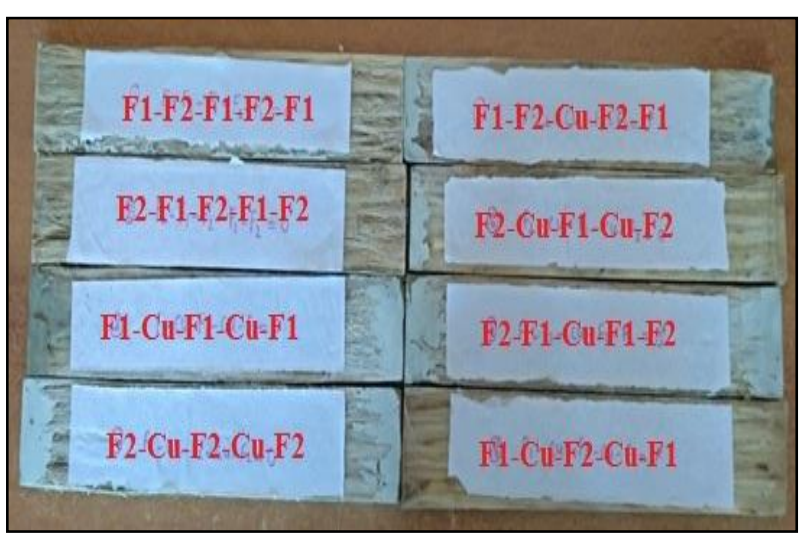

Fig. 6. Composites with $0^{\circ}$ orientataion used for Hardness testing

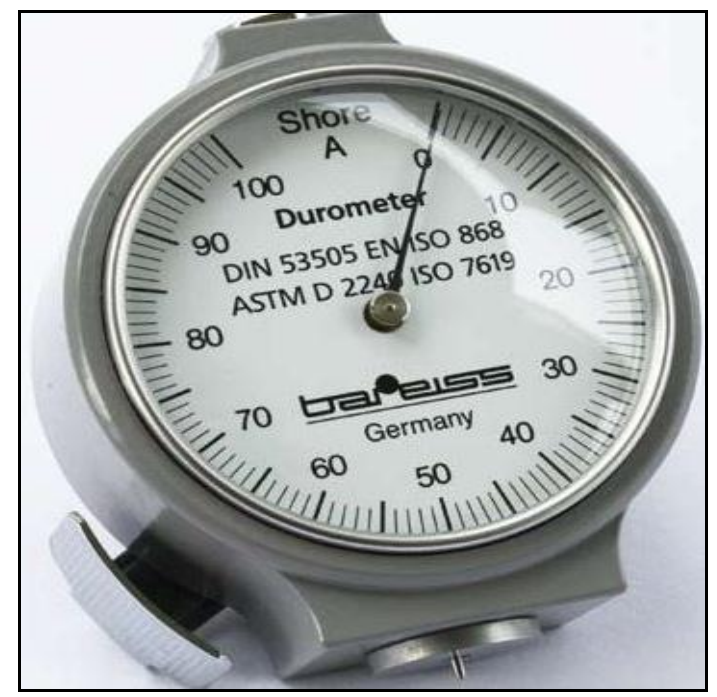

Fig. 7. Shore-A hardness tester 


\subsection{Bending test}

A bending test is a method for measuring stiffness and yield properties of certain materials. In the present work, a three point flexural test is used, the main advantage of which is the ease of the specimen preparation and testing. The bending test is done using universal testing machine (UTM). A UTM is used to determine a material's response to varying strains, called loads. The (TUE/TUE-C-00 UTM) used for testing the composite samples is of $400 \mathrm{KN}$ capacity with an accuracy of $\pm 1 \%$ within $2 \%$ to $100 \%$ of the range and a ram stroke of 200 $\mathrm{mm}$.

The fabricated composites were sheared according to standards. The dimensions of specimens used for the bending test are $150 \mathrm{~mm}$ X $40 \mathrm{~mm}$ X $6 \mathrm{~mm}$ each and the test is carried out until failure takes place. When the load is applied, the deflection and bending strength corresponding to each load is calculated and the results are given in the display. Figure 8 shows the UTM with a specimen during bending test and Figure 9 shows the specimens after being tested on UTM. The tensometer instruments provided on the UTM give load as a function of extension. By using this data, a loaddeflection curve or stress-strain curve will be plotted. This curve is unique for every material and provides key measures.

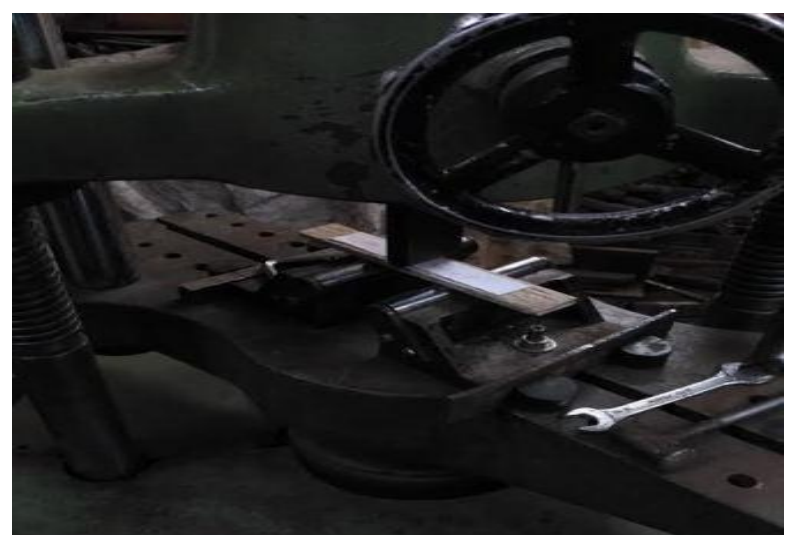

Fig.8. Sample while testing for bending strength on UTM

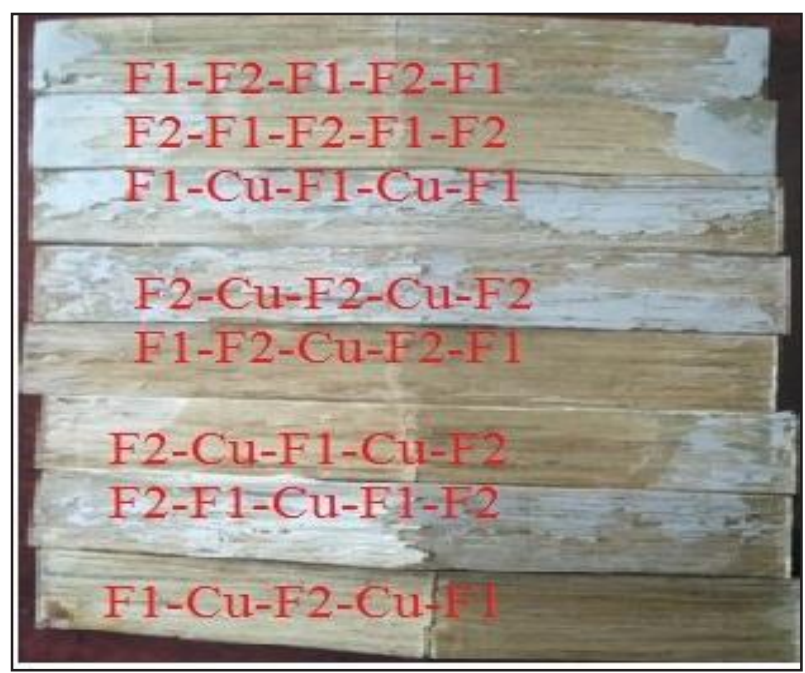

Fig. 9. Specimens after bending test for Composites with $0^{\circ}$ orientation

\section{Results and Discussions}

Figure 10 shows the comparison of hardness of composites with $0^{\circ}, 45^{\circ}$ and $90^{\circ}$ orientations. It is observed from the bar chart that, the hardness of $\mathrm{F} 2-\mathrm{Cu}-$ $\mathrm{F} 1-\mathrm{Cu}-\mathrm{F} 2$ composite with $90^{\circ}$ orientation is high (95 Shore -A hardness number) and that ofF1-F2-F1-F2-F1 composite with $45^{\circ}$ orientation is low (73 Shore-A hardness number). Figure 11 shows the comparison of bending strengths of composites with $0^{0}$ and $45^{\circ}$ orientations. It is observed from the bar chart that, the bending strength of $\mathrm{F} 2-\mathrm{Cu}-\mathrm{F} 1-\mathrm{Cu}-\mathrm{F} 2$ composite with $0^{\circ}$ orientation is high (9.32 MPa) andF2-F1-F2-F1-F2 composite with $45^{\circ}$ orientation has the low strength (3.856 MPa).The results for $90^{\circ}$ orientation are not obtained.

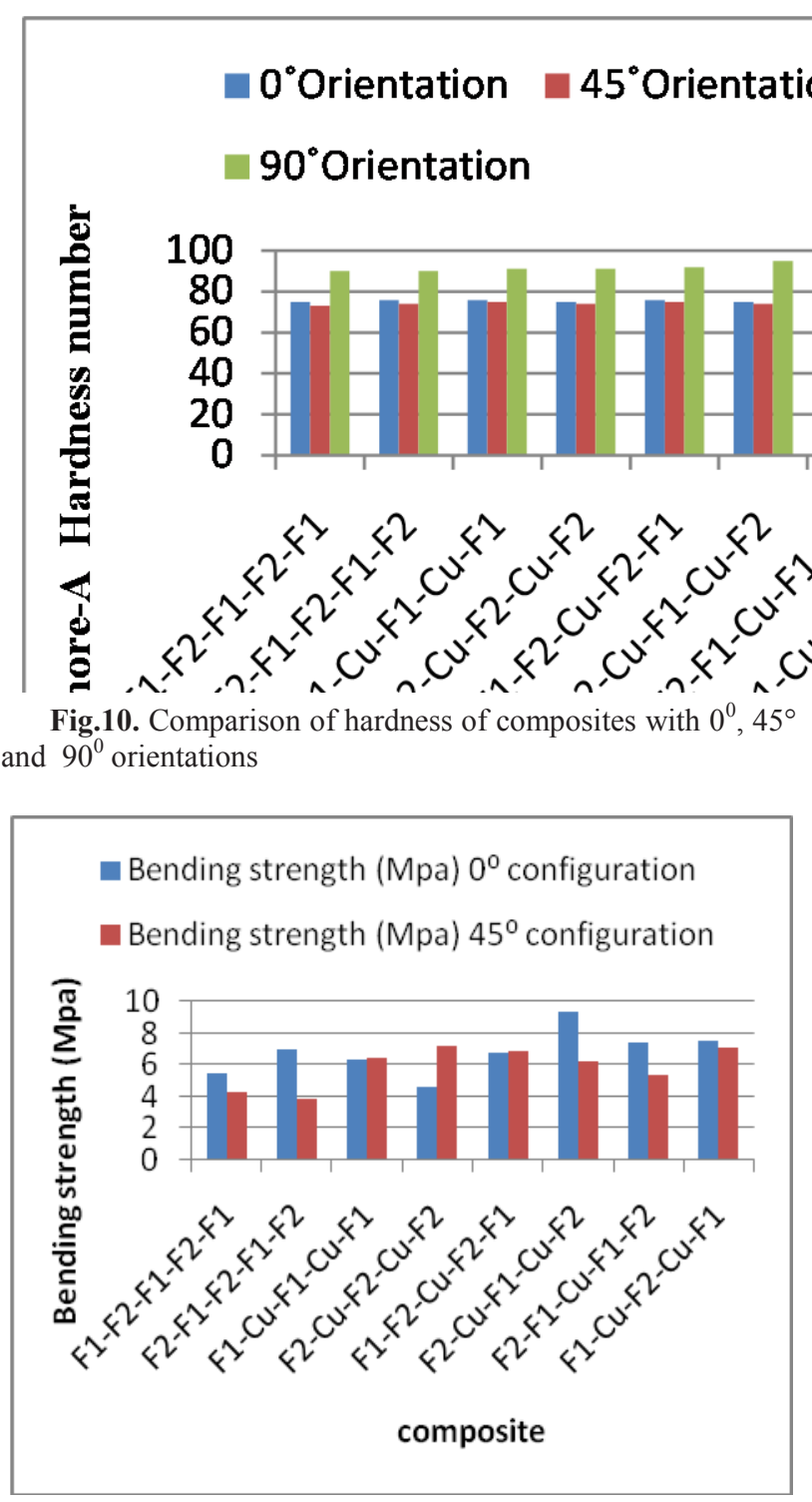

Fig.11. Comparison of bending strengths of composites with $0^{0}$ and $45^{\circ}$ orientations

\section{Conclusions}

In the present work, the hardness and flexural behaviour of Banyan and Peepal fibre reinforced hybrid composites was studied. The investigation includes fabrication of 
composites through hand lay-up technique, and evaluation of hardness and flexural properties as per the experimental plan. The major contributions drawn from the investigation are summarized as below:

$>$ The hand lay-up technique was successfully adopted in the fabrication of Banyan and Peepal fibre reinforced hybrid composites.

$>$ The hardness of F2-Cu-F1-Cu-F2 composite with $90^{\circ}$ orientation is high (Shore-A hardness number=95) and that of F1-F2-F1-F2-F1 composite with $45^{\circ}$ orientation is low (Shore-A hardness number $=73$ ).

$>$ The hardness of all the composites with $45^{\circ}$ orientation is low compared to their $0^{\circ}$ and $90^{\circ}$ orientations.

$>$ The hardness of all the eight composites with $90^{\circ}$ orientation is found to be high compared to their remaining orientations.

$>$ The bending strength of $\mathrm{F} 2-\mathrm{Cu}-\mathrm{F} 1-\mathrm{Cu}-\mathrm{F} 2$ composite with $0^{0}$ orientation is high $(9.32 \mathrm{MPa})$ and that of $\mathrm{F} 2-$ F1-F2-F1-F2 composite with $45^{\circ}$ orientations is low (3.856 MPa).

$>$ Except for the F1-Cu-F1-Cu-F1 composite, F2-CuF2-Cu-F2 composite and F1-F2-Cu-F2-F1 composite the bending strength of all the composites with $0^{\circ}$ orientation is high compared to their $45^{\circ}$ orientations.

On an overall perspective, within the purview of the present study, better flexural strength has been obtained for the Banyan-Peepal fibre reinforced hybrid composite with Copper as one of the elements in it.

\section{References}

1. Joshi, S. V., Drzal, L. T., Mohanty, A. K. and Arora, S, Composites: Part A, Vol. 35, pp. 371-376 (2004)

2. Rana, A.K., Mitra, B.C. and Banerjee, A.N., J.Appl.Polym. Sci.71:pp.531-539(1999)

3. Shah and Lakkad, Fibre science and technology15, 4146(1981)

4. Ray, B.K. Sarkar, A.K.Rana, N.R.Bose, Part A 32, pp.119-127(2001)

5. ProsenjitSaha, Suvendu Manna, Sougata Roy Chowdhury, RamkrishnaSen, Debasis Roy, BasudamAdhikari, Bio resource Technology, 101:9, 3182-3187(2010)

6. Monteiro S.N Rodrikuez, R.J.S. De Souza, M.V.D'Almeida J.R.M., Advanced Performance Material, 5:3 ,183-191(1998)

7. Hassan M.L.Rowel,1 R.M.,Fadl N.A., Yacoub S.F. and Chrisainsen.A.W, Journal of applied polymer science, 76, 575-586(2000)

8. Ramesh, M., Palanikumar, K. and Reddy, K.H,. Composites: Part B, 48, 1-9(2013)

9. Alavudeen.A,Rajini.N,Karthikeyan.S,Thiruchitrambalam.M and Venkateshwaren.N,Materials and Design, 66, 246-257(2015). 